\title{
Design of a Mobile Application for the Learning of People with Down Syndrome through Interactive Games
}

\author{
Richard Arias-Marreros ${ }^{1}$ \\ Keyla Nalvarte-Dionisio ${ }^{2}$ \\ Laberiano Andrade-Arenas ${ }^{3}$ \\ Facultad de Ciencias e Ingeníeria \\ Facultad de Ciencias e Ingeníeria \\ Facultad de Ciencias e Ingeniería \\ Universidad de Ciencias y Humanidades Universidad de Ciencias y Humanidades Universidad de Ciencias y Humanidades
}

\begin{abstract}
The research work is focused on people with Down syndrome since it is the most common genetic disorder worldwide, also, these people have cognitive and visual-motor disabilities, however, the Peruvian state does not use even $1 \%$ of the budget allocated to the educational sector of these people, so, by not receiving the education they can not develop their skills. Therefore, a prototype of a mobile application was designed for the learning of people with Down syndrome through interactive games, implementing the Scrum methodology for the development of the application prototype, using the Troncoso method for the teaching of reading and writing, but the teaching of visual-motor coordination was added to the method and concerning the design of the prototype, the Balsamiq tool was used because it was the most appropriate. And so the objective of developing the prototype of the application was achieved. Having as a result that people with Down syndrome can read or write basic words and differentiate the hemispheres of their body, through the unlimited attempts of the exercises, in each level or type of learning. In this way, with the teachings received, these people will have a better quality of life, being able to integrate into society, and be more independent when performing daily activities.
\end{abstract}

Keywords-Application of games; cognitive disabilities; Down's Syndrome; scrum methodology; Troncoso Method

\section{INTRODUCTION}

Currently, Down syndrome is the most common genetic disorder worldwide and is one of the main causes of intellectual disability that affects people, generating a major problem in the functionality and independence to perform daily activities [1]. It can also be said that the visual-motor cognitive ability is one of the most sensitive, and it is a fact that this cognitive ability can be improved in people with Down syndrome [2].

In Europe, in the period 2011 to 2015, there is an estimated annual 7,800 born with Down syndrome, which corresponds to a predominance of 9.8 per 10,000 births [3]. Similarly, in Peru, according to Conadis, in 2015 there will be a total of 141,731 people with disabilities, of which 8,800 suffer from Down's syndrome, $6.21 \%$ of the total number registered, and the number is increasing every year [4].

A characteristic of people with Down syndrome is that they may have difficulty learning numbers compared to letters. They need personalized learning because their learning rate is slower [5]. However, these people not only face a motor and intellectual disability but also barriers that can hinder their full and effective participation in society [6]. Besides, people with Down syndrome have different levels of IQ. Some of them don't even know how to speak and interact, but some are smart and can learn well [5].

Because of the above, there are several approaches to teaching different skills to students with learning and behavior problems, for example, one method to teach people with Down syndrome is the method of Troncoso that is designed to recognize written words as a whole rather than divide them into letters and its philosophy is to recognize the meaning of the symbols that are written [7]. However, the use of information technology in special education can improve the ability in the learning process, beyond being entertainment is a teaching tool that will help you in the development of cognitive and visualmotor skills [6].

The application will help people with Down syndrome because they do not have much support in the educational sector. After all, in-state schools there are no people trained to teach, apart from that, the use of technology as a learning tool will help the development of cognitive ability, since you would be learning, but at the same time playing.

Also, this game will be a complement to conventional motor therapies, which aim to provide support to professionals in the area and generate performance reports for further analysis and thus monitor the process of developing their skills [1].

The objective of the article is to design a mobile game application for people with Down syndrome improving the development of cognitive and visual-motor skills through an interaction between the person and the application.

The rest of the document was organized as follows: Section II will define the Scrum methodology, the Troncoso method, and tools to be used, Section III will show the case study, Section IV will show the discussions, Section V will show the results, and finally Section VI will show the conclusion.

\section{Methodology}

In this article, we will implement the Troncoso method, the Scrum methodology, and some technological tools to develop a mobile application prototype for the learning of people with Down syndrome through interactive games. 


\section{A. Troncoso Method}

Teaching people with Down syndrome to read is a very difficult activity that requires special pedagogical techniques. This syndrome causes disorders in the cognitive mechanism of attention, alertness, memory, correlation, analysis, and abstract thinking. Also, the visual-motor cognitive ability of these people is not fully developed, since a child with Down syndrome can not distinguish the hemispheres of the body [1].

Table I shows the percentage of people with Down syndrome in Spain according to the relation of activities since there is a high percentage that lacks illiteracy from 15 years old and only a low percentage that is in high school, making it known that there is no support for people to develop educational aspects.

TABle I. Population of SPAin With Down SYNDROME AGED 16 AND OVER ACCORDING TO AGE AND RELATIONSHIP WITH ACTIVITY (PERCENTAGES)

\begin{tabular}{|l||l|l|l|l|}
\hline & $\begin{array}{l}\text { Of 15 to } \\
29\end{array}$ & $\begin{array}{l}\text { Of 39 to } \\
44\end{array}$ & $\begin{array}{l}\text { Of 45 to } \\
59\end{array}$ & $\begin{array}{l}\text { Whole popu- } \\
\text { lation }\end{array}$ \\
\hline $\begin{array}{l}\text { He does not } \\
\text { know to read } \\
\text { nor to writes }\end{array}$ & 36,8 & 60,9 & 79,9 & 55,39 \\
\hline $\begin{array}{l}\text { Incomplete } \\
\text { primary } \\
\text { studies }\end{array}$ & 41,9 & 24,8 & 13,7 & 29,34 \\
\hline $\begin{array}{l}\text { Primary or } \\
\text { equivalent } \\
\text { studies }\end{array}$ & 18,1 & 12,4 & 3,5 & 13,4 \\
\hline $\begin{array}{l}\text { 1st stage sec- } \\
\text { ondary educa- } \\
\text { tion }\end{array}$ & 3,2 & 1,9 & 2,9 & 2,47 \\
\hline Total & 100,0 & 100,0 & 100,0 & 100,0 \\
\hline
\end{tabular}

Table II shows the number of people in Peru who have some kind of deficiency that prevents them from developing intellectually, linguistically, visually, or morally, etc.

TABLE II. POPULATION WITH DOWN SYNDROME REGISTERED IN THE National Registry of PERSONS With Disabilities, By TYPE OF IMPAIRMENT

\begin{tabular}{|l||l|}
\hline Type of deficiency & Quantity \\
\hline Intellectuals & 8388 \\
\hline Other mental & 6494 \\
\hline Of language & 7798 \\
\hline Of audition & 775 \\
\hline Of vision & 1734 \\
\hline Visceral & 1852 \\
\hline Musculoskeletal & 3695 \\
\hline Others & 1556 \\
\hline
\end{tabular}

Because of this, it takes into account all the characteristics that are concluded with learning, as it is slow and it is necessary to follow a step-by-step process. Currently, there are educational methods designed for people with Down syndrome, one of them is the Troncoso method.

The Troncoso Method is a reading and writing teaching system designed specifically to work with people with Down syndrome. Also, it aims to ensure that students acquire a reading and writing ability good enough to have an independent life, trying to manage functionally and practically with their social and cultural environment [8].

1) Stages of reading instruction: It is done in the opposite way to the usual. Instead of teaching the child to recognize the fundamental units of words, it begins by helping him/her recognize some simple words through the use of pictures. The objective of the first stage is to make the child capable of recognizing written words based on their shape, without the need to know the individual letters. In the second stage, the objective is to help recognize the syllables by which words are formed so that they can be identified in other written texts [9].

2) Stages of teaching writing: It is divided into three phases, ranging from the most general and simple skills to the most complicated. In the first stage, you have to become familiar with the use of pencil and paper by drawing basic lines and shapes. In the second phase, the student will apply the skills acquired during the previous phase and will have to learn to write letters. Later, he or she must be able to put them together in syllables, words, and sentences. Finally, the final stage of the teaching of writing has to do with acquiring greater speed and fluency in reproducing all types of written texts [9].

3) Stages of teaching visual-motor coordination: The following stages of teaching do not belong to the Troncoso method, since that method only teaches reading and writing, but will be a perfect complement to the development of motor skills of people with Down syndrome. The teaching of visualmotor coordination consists of three different stages, but before the first stage, the same user or with the help of a person will place the mobile device in front, for example, on a table or shelf and must be standing at a distance of five or six feet.

The first stage is a presentation of concepts of the hemispheres, clearly showing the child which of each side is the left and which is the right [1]. After the presentation, the front camera will be activated and the user will be able to look at himself as in a mirror, at that moment an assistant will be shown that will order him to move his arms or legs from the bottom to the top, then he will be asked to move a specific arm, either right or left, if the user succeeds the assistant will congratulate him, but if he fails it will motivate him and will give him another order so he can keep on trying and can achieve the exercise.

\section{B. Scrum Methodology}

Scrum is a software development model that helps establish successful and organized step-by-step projects. Agility is what most characterizes the methodology, so it was chosen to implement in the project.

1) Processes: The methodology consists of four processes, and they are the following:

a) Sprint Planning: In this meeting, we will define the functionality in the planned increment and how it is being developed in the increment and output defining the objective that Sprint will have [10].

b) Sprint development work: This process of the methodology will make use of the Sprint Backlog tool, and each team member inspects the work that the rest is doing [11], also, no changes can be made so as not to affect the objective of the Sprint in process, the quality is maintained and if a Sprint is too large can increase the complexity, but also increase the risk. 
c) Sprint Review: The review process is done at the end of each Sprint lasts approximately 4 hours, so that the increase can be inspected in detail. The interested parties and the Scrum team are the collaborators of the revision, besides, it is directed by the Product Owner who is in charge of watching over the fulfillment of the established. The result of this process is a Product Backlog with some possible changes in its estimate [10].

d) Retrospective of the Sprint: It is an opportunity for the team to inspect themselves for errors they may have made, and to create a plan for improvements in the next Sprint, with a time frame of approximately 4 hours [10]. And after this process, the cycle starts again after the Sprint.

2) Tools: The methodology has two important tools, and they are:

a) Product Backlog: It is a list of tasks that encompasses the entire project, managed by the Product Owner defining the order and priority. The list has a dynamic character and can change at the end of each Sprint [10].

b) Sprint Backlog: It is a subset of the Product Backlog tasks that the development team chooses for the Sprint, along with the plan to develop it [10].

Fig. 1 represents the order of the processes, how they are developed, and the use of tools.

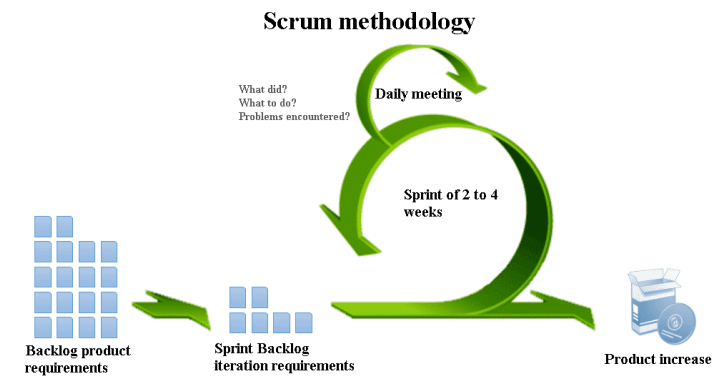

Fig. 1. Scrum Methodology Processes

\section{Prototype Tools}

For the design of the mobile application, we will use Balsamiq Wireframes, which is a graphic design tool for user interfaces, either for websites and desktop or mobile web applications [12]. The advantage of this tool is its interactivity when making the designs and the accessibility of the software.

\section{Technological Tools}

The following tools will be used for the development of the mobile application prototype.

1) Android Studio: The environment that will be used to develop the mobile application will be Android Studio, which is the official integrated development environment (IDE) for Android application development, based on IntelliJ IDEA. It is one of the best code editors and has many tools for Intellij [13]. Also, it is characterized, by being a fast emulator, with many functions, tools, with a wide variety of API (application programming interface) that you can use for any development project of a mobile application.

2) Kotlin: To develop the application, we will use the Kotlin language, which is a fairly modern programming language that simplifies the work, increases productivity, and leaves the developer satisfied [14]. It has a more secure, more concise, and optimal code concerning asynchronous programming.

3) SQLite: Regarding the database, the best option would be SQLite, which is a $\mathrm{C}$ language library that has implemented a small, fast, autonomous, highly reliable SQL database engine with almost all the functions [15]. It is the most widely used database engine in the world, is integrated into absolutely all cell phones and a large part of computers, and is included in almost all applications that people use.

\section{CASE STUdy}

In this section of the research, the development of the mobile application prototype will be explained in detail, along with the methodologies mentioned, because it will perform the processes according to the requirements to have the prototype. Next, the planning of the Sprint of each of the modules to be exercised and the estimation of the time spent in each of the development stages will be carried out.

\section{A. Sprint Planning}

In this section will be made the User History that are descriptions of the functionalities that will have the software and will be the result of the collaboration between client and team and will be improved during the life of the project, besides, they are of fast forms to administer the requirements without elaborating great documents[16], next, the following format will be placed for the user history As, I want and for; that will be developed in the case of study.

- As a User, I want to enter the application through an account generated to access the application.

- As a User, I want to register to add my data to have an account and enter the application.

- As a User, I want to make the entrance evaluation to know at which level I am.

- As a User, I want to choose the learning method according to my preference and the results of the entrance test to acquire knowledge according to my level.

- As a User, I want to visualize the reports of my test scores to have control of my learning.

1) Time Estimation: In this phase, the duration of each of the Sprints is, observed, as shown in Table III. One of the best-known techniques used to estimate in Scrum is Planning Poker, which uses an arbitrary size measure to indicate the complexity in the size of a user story and whose value only makes sense to the development team in question [17]. The estimation of the project resulted in three months because the user stories were estimated between one or two weeks. 
TABLE III. PRODUCT BACKLOG

\begin{tabular}{|l|l|}
\hline Interface & Duration \\
\hline $\begin{array}{l}\text { Mobile application for learn- } \\
\text { ing development }\end{array}$ & 3 months \\
\hline Sprint1: Login Interface & 1 week \\
\hline Sprint1:Registration Interface & 2 weeks \\
\hline $\begin{array}{l}\text { Sprint2: Input Evaluation In- } \\
\text { terface }\end{array}$ & 2 weeks \\
\hline $\begin{array}{l}\text { sprint3: Written Learning In- } \\
\text { terface }\end{array}$ & 2 weeks \\
\hline $\begin{array}{l}\text { Sprint3:Reading Learning In- } \\
\text { terface }\end{array}$ & 2 weeks \\
\hline $\begin{array}{l}\text { Sprint3:Coordination } \\
\text { Learning Interface }\end{array}$ & 2 weeks \\
\hline Sprint4: Reports interface & 2 weeks \\
\hline
\end{tabular}

2) Product Scope: It can be understood as the characteristics that the product has as a result of a project. The functionalities that it has originated from a series of requirements given by the client or the executing organization, which indicate how the product is wanted. Therefore, if you want to know if the scope of the product was met, it is verified and evaluated that all requirements raised that are included within the resulting product, that is, it is as requested[18].

Fig. 2 shows the estimate of the time it will take for the equipment to have the points of the user history so that the estimates of the scope of the equipment are noted in the least detail.

\section{PRODUCT CONSUMPTION TABLE}

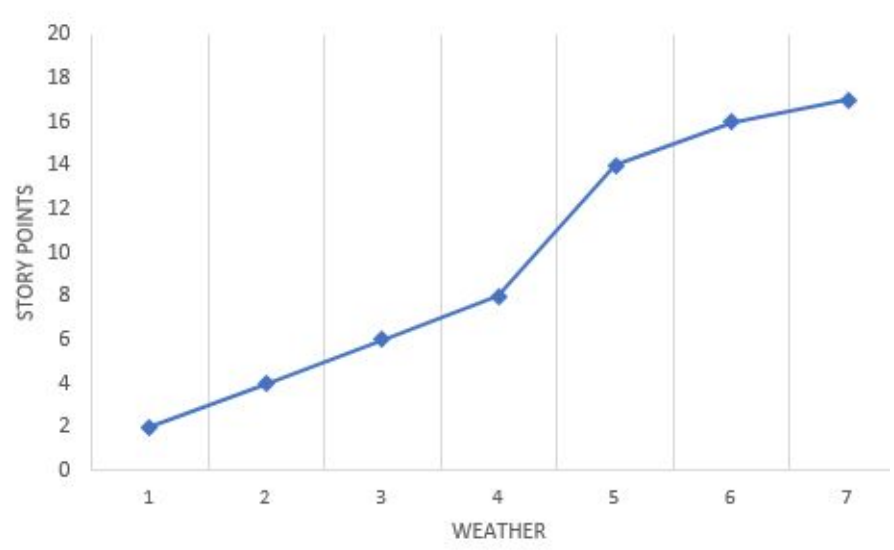

Fig. 2. Product Scope

\section{B. Sprint Development Work}

The Sprints developed in this process are:

1) Sprint 1 (Login and Registration): In this Sprint, the prototypes of the user login and registration interfaces were developed. The user will be able to enter his account with an email and a password, as shown in the login interface in Fig. 3 . If you do not have an account you can register, as shown in the login interface in Fig. 3, you will have to enter your data such as your full name, age, gender, date of birth, email, and password.
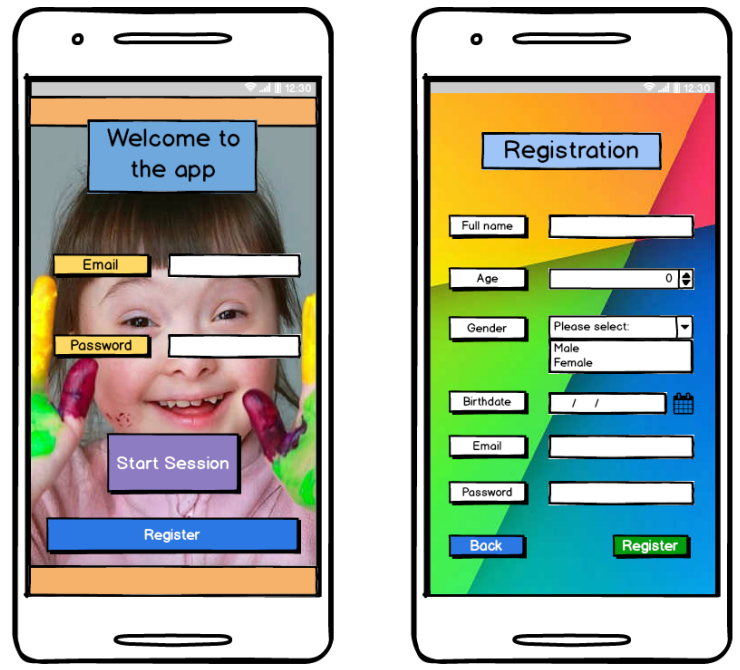

Fig. 3. Login and Registration

2) Sprint 2 (Input evaluation): In this second Sprint, the prototype of the input evaluation interface was developed to determine the user's level of knowledge. As shown in Fig. 4, the interface has three sections, one for writing, one for reading, and one for coordinating movements.

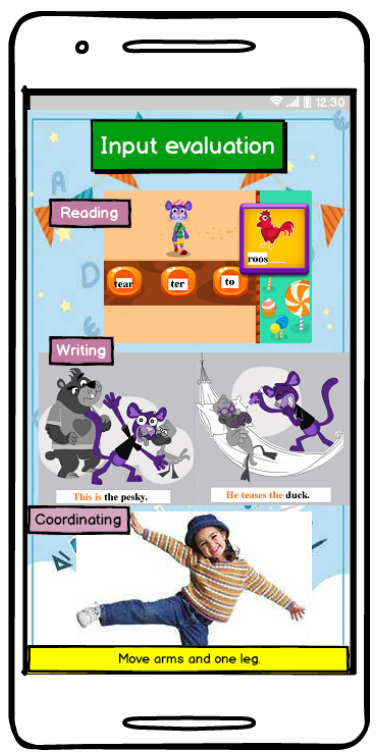

Fig. 4. Input Evaluation

3) Sprint 3 (Learning to write, read, and coordinate movements): In this Sprint was developed the prototype of the learning interfaces for the user, as shown in Fig.5 is the writing interface, there the user will learn to write the words correctly, the exercise consists of completing a word, where you will have three alternatives, and only choose one that is correct, also at the top of the word is a picture of support.

The reading interface is shown in Fig. 5, there the user will learn to read texts, the exercise consists of reading small stories, while reading, the words read will be shaded. If you do not read it correctly, the word will not be shaded, you will 

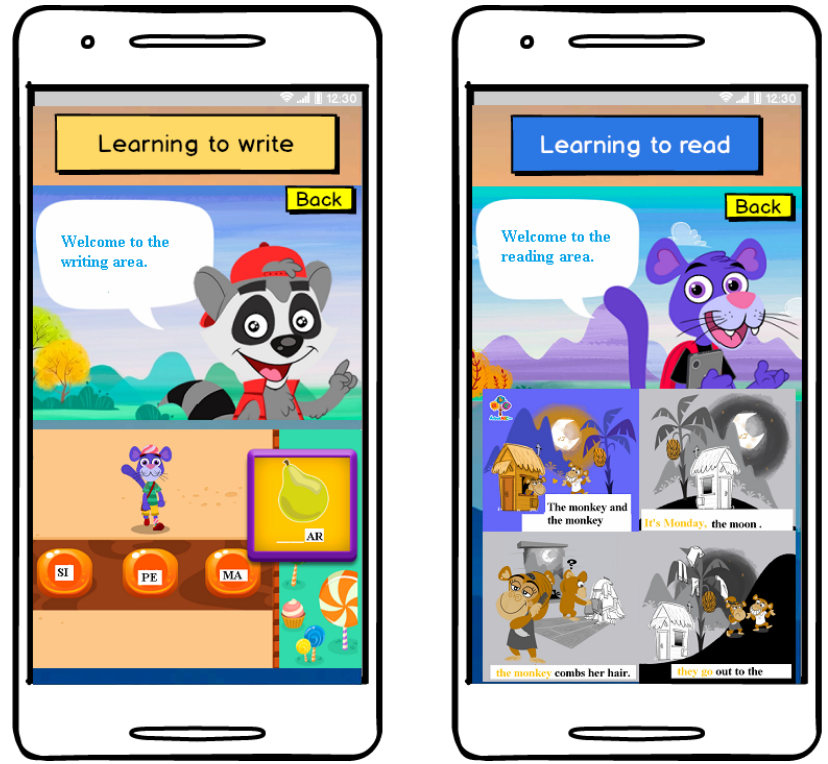

Fig. 5. Teaching Writing and Reading

have to read it again so that everything is shaded and thus complete the exercise.

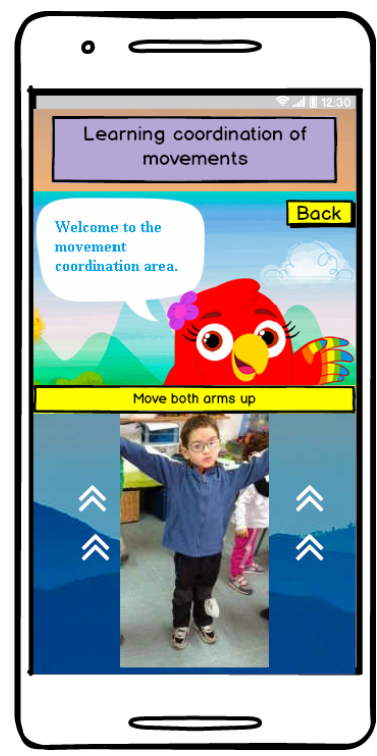

Fig. 6. Teaching Coordination

The interface shown in Fig. 6, has the objective that the user learns to recognize the right and left hemisphere, making movements of his arms or legs. As an example, we show a child who is looking at the front camera of the cell phone and is doing the action of raising both hands, because the application tells him to move to his right and left arm upwards. Another example is shown in Fig. 5 in the lower part where the learning of movement coordination is, the girl receives the indication to raise her right hand and leave her left hand down, but she also raises her right leg, but the application considers that she correctly fulfilled what was indicated.
4) Sprint 4 (Report on learning): In this last Sprint, the prototype of the interface for reporting the user's learning was developed, as shown in Fig. 7, the user will see the progress he has in the three learning, the first bar graph measures the number of correct answers in each learning and it is seen that it stands out in the reading. Also, a pie chart is generated showing a total of the correct answers per month, and it is seen that in November the user had more correct answers than in previous months.

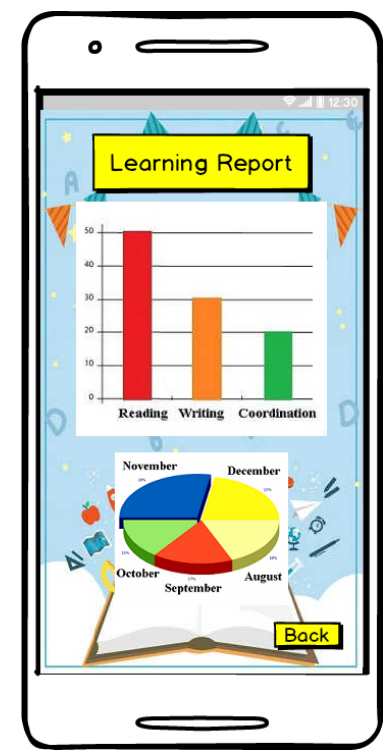

Fig. 7. Report on Learning

\section{Sprint Review}

When the Sprint is finished, it is inspected by the team, with the review time of two to three hours. One of the team members will evaluate each task developed and decide if any changes are needed. Also, the team members will explain each process in detail and the solutions that were implemented.

\section{Retrospective of the Sprint}

The team evaluates each process and technique implemented during the development of the Sprint. For example, the use of the Kotlin programming language, the SQLite database manager, or the Balsamiq tool for the development of the prototypes. New ideas or methods can be suggested for the gradual improvement of each Sprint of the project.

\section{DISCUSSION}

In this section, the analysis will be carried out and compared with other researches, of which they present similarities or inequality concerning the development of the methodology chosen for the application, taking into account the phases involved in it and in its way of presenting the execution.

\section{A. About Case Study}

The prototype was made with Balsamiq because it is a simple and accessible tool so that the functionalities were reviewed and approved by the team. Compared to another 
application called Hatle that was made with Android Studio, for children who can not read or write [19], the design was improved so that the user does not have difficulties with the application, increasing tests so you can see your progress.

\section{B. About the Methodology}

The Scrum methodology compared to the RUP methodology, has some controversy, has some essential characteristics of agile development processes such as iterative growth or is focused on the architecture, but in turn the rigidity of conventional methods [20].

Among other advantages that the Scrum methodology highlights, is the adaptation to a wide range of software development projects where development teams are small, with short deadlines, and high levels of quality [21].

Some limitations that were found in the research work that could have affected the results, was not choosing a good method that is very useful for people with Down syndrome can learn correctly in the application, and another is that there was not much application research done.

\section{RESUlTS}

Next, we will show the expected results regarding the development of the research within the case study and the methodology, taking into account the application to be developed and the implementation of the control system.

\section{A. About Case Study}

As a case study, the objective was to develop a learning tool for people with Down syndrome by improving the development of their cognitive and motor skills based on technologies, determining the effectiveness by comparing the progress of literacy, using measures of letter identification, reading, spelling and handwriting quality.

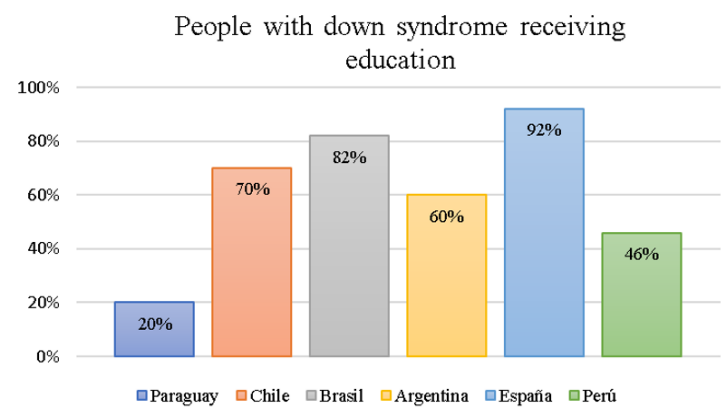

Fig. 8. People with Down Syndrome Receiving Education in Some Countries

Fig. 8 shows that countries like Peru and Paraguay have a low percentage of people with Down syndrome who receive an education. And of this percentage, only a small group of people receive it in specialized schools.

And current studies support the hypothesis that, through appropriate applications of the tablets, special students with disabilities or learning difficulties can enrich their literacy skills [19].
However, the use of this technology, while producing improvements in spatial reasoning and visual attention, does not produce the same effect in selective attention [22]. Furthermore, as we can see in Fig. 9, the data collected by the Inclusive Education Group of the Salesian Polytechnic University in the current research situation of the use of technology as an assistive resource in the education of students with disabilities shows that it is of great help to them.

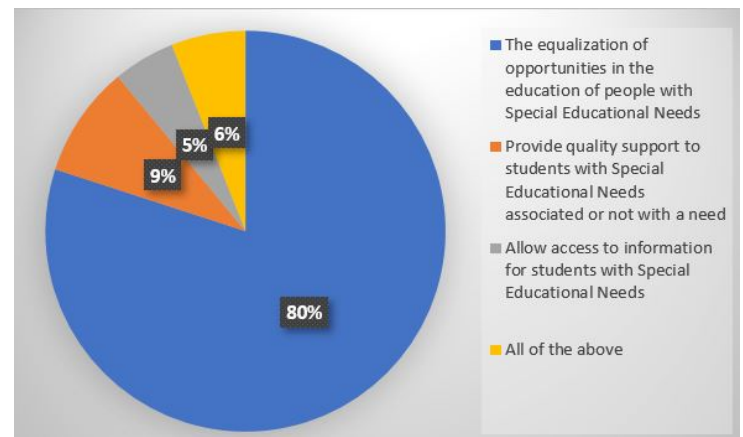

Fig. 9. Benefits of the use of ICT in the Education of Persons with Disabilities

\section{B. About the Methodology}

The implementation of the Scrum methodology, allowed to generate a comfortable work environment for the whole team because they worked collaboratively [23]. Besides, it has a structure that divides processes and tools easy to understand and develop.

\section{CONCLUSIONS}

We developed the prototype of the application that will help people with Down syndrome to develop their cognitive and visual-motor coordination skills through interactive games with the Balsamiq tool that is well known for interface design. And with the implementation of the Scrum methodology and the Troncoso method allowed better teamwork. In this way, with the teachings received through the interactive games, people with Down syndrome will be able to integrate into society, be more independent in their daily activities and thus have a better quality of life. As future work, we want to develop the application implementing artificial intelligence and adding more interactive games in the different learning so that the user does not get bored with the same games and have more fun and optimal learning.

\section{REFERENCES}

[1] T. Rodrigues, N. Valencia, D. Santos, A. Frizera, and T. Bastos, "Development of game-based system for improvement of the left-right recognition ability in children with down syndrome," pp. 627-634, 2019.

[2] P. V. Torres-Carrión, C. S. González-González, P. A. Toledo-Delgado, V. Muñoz-Cruz, R. Gil-Iranzo, N. Reyes-Alonso, and S. HernándezMorales, "Improving cognitive visual-motor abilities in individuals with down syndrome," Sensors, vol. 19, no. 18, p. 3984, 2019.

[3] G. de Graaf, F. Buckley, and B. G. Skotko, "Birth and population prevalence for down syndrome in european countries," 2018.

[4] G. Castro and R. Jhonatan, "Síndrome de down en el perú," Multimedia Tools and Applications, p. 4, 2020.

[5] W. F. W. Ahmad, H. N. B. I. Muddin, and A. Shafie, "Number skills mobile application for down syndrome children," pp. 1-6, 2014. 
[6] N. S. Abdul Aziz, W. F. W. Ahmad, and N. J. b. Zulkifli, "User experience on numerical application between children with down syndrome and autism," pp. 26-31, 2015.

[7] K. Caro, I. A. Encinas-Monroy, V. L. Amado-Sanchez, O. I. IslasCruz, E. A. Ahumada-Solorza, and L. A. Castro, "Using a gesture-based videogame to support eye-hand coordination and pre-literacy skills of children with down syndrome," Multimedia Tools and Applications, pp. $1-28,2020$.

[8] N. M. Rubio, "Método troncoso: qué es y cómo se aplica en niños y niñas," urlhttps://psicologiaymente.com/desarrollo/metodo-troncoso, 2016.

[9] R. P. Alejandro, "Troncoso method: what is it for, materials, stages," urlhttps://www.lifeder.com/metodo-troncoso/, 2020.

[10] J. C. A. Becerra and C. E. D. Vanegas, "Propuesta de un método para desarrollar sistemas de información geográfica a partir de la metodología de desarrollo ágil-scrum." Cuaderno Activa, vol. 10, pp. 29-41, 2018.

[11] M. S. Méndez Ramos, J. Preciado Garcia, D. P. Castrillón Arboleda et al., "Modelo de transición de metodología rup a scrum en proyectos de desarrollo de software."

[12] Balsamiq, "What tools does balsamiq offer to help remove bad software from the world?" urlhttps://balsamiq.com/company/, 2020.

[13] Developer.Android, "Introduction to android studio," urlhttps://developer.android.com/studio/intro, 2020.

[14] Developer, "How to develop android apps with kotlin?" urlhttps://developer.android.com/kotlin?hl=es, 2019.

[15] SQLite, "What is sqlite?" urlhttps://www.sqlite.org/index.html, 2020.

[16] K. V. Suaza, J. J. T. García, and C. M. Z. Jaramillo, "Mejora de historias de usuario y casos de prueba de metodologías ágiles con base en tdd."
Cuaderno activa, vol. 7, pp. 41-53, 2015.

[17] J. G. F. Mendoza, F. G. Vera, C. C. O. González, and A. S. Contreras, "Propuesta metodológica para la estimación de proyectos gestionados mediante scrum, con enfoque a la pequeña industria del software (methodological proposal for estimating projects managed in scrum, focusing on small business software industries)," Pistas Educativas, vol. 41, no. 134, 2019.

[18] R. B. Miguel, "Product scope vs. project scope," urlhttp://www.liderdeproyecto.com/articulos/, 2019.

[19] V. G. Felix, L. J. Mena, R. Ostos, and G. E. Maestre, "A pilot study of the use of emerging computer technologies to improve the effectiveness of reading and writing therapies in children with down syndrome," British Journal of Educational Technology, vol. 48, no. 2, pp. 611-624, 2017.

[20] D. A. V. Paredes, L. C. C. Martínez, R. M. L. Bermúdez, and S. R. P. Mendoza, "Análisis de la metodología rup en el desarrollo de software académico mediante la herramienta django," RECIMUNDO, vol. 3, no. 2, pp. 964-979, 2019.

[21] A. Kuz, M. Falco, and R. S. Giandini, "Comprendiendo la aplicabilidad de scrum en el aula: herramientas y ejemplos," Revista Iberoamericana de Tecnología en Educación y Educación en Tecnología, no. 21, pp. $\mathrm{e} 07-\mathrm{e} 07,2018$.

[22] A. Adrián, "La tecnología, gran aliada de los alumnos con down," urlhttps://www.magisnet.com/2019/04/la-tecnologia-gran-aliadade-los-alumnos-con-down/, 2019.

[23] N. Tymkiw, J. M. Bournissen, and M. C. Tumino, "Scrum como metodología de enseñanza y aprendizaje de la programación," in XXII Workshop de Investigadores en Ciencias de la Computación (WICC 2020, El Calafate, Santa Cruz), 2020. 